

\section{A History of the NBS Time and Frequency Dissemination Services}

Mar. 1923 First scheduled broadcasts of WWV, Washington, DC

Apr. 1933 WWV gets first $20 \mathrm{~kW}$ transmitter, Beltsville, MD

Jan. 1943 WWV relocated to Greenbelt, MD

Nov. 1948 WWVH commenced broadcasts, Maui, HI

Jan. $1950 \mathrm{WWV}$ added voice announcements

Jul. 1956 WWVB (KK2XEI) began $60 \mathrm{kHz}$ broadcasts, Boulder, CO

Apr. 1960 WWVL began $20 \mathrm{kHz}$ experimental broadcasts, Sunset, CO

Jul. 1963 WWVB began high power broadcasts, Ft. Collins, CO

Aug. 1963 WWVL began high power broadcasts, Ft. Collins, CO

Jul. 1964 WWVH added voice announcements

Dec. 1966 WWV relocated to Ft. Collins, CO

Jul. 1971 WWVH relocated to Kauai, HI

Jun. 1972 First "leap second" in history added to UTC time scale

Jul. 1972 WWVL transmissions curtailed

Jan. 1974 Voice announcements changed from Greenwich Mean Time to Coordinated Universal Time (WWV and WWVH)

Mar. 1975 Frequency calibration using network color TV became a nationwide service

Aug. 1975 Line-10 time comparisons using TV synchronization pulses became a nationwide service 
NBS

TIME AND FREQUENCY

DISSEMINATION SERVICES

Sandra L. Howe, Editor

Time and Frequency Division

Institute for Basic Standards

National Bureau of Standards

Boulder, Colorado 80302

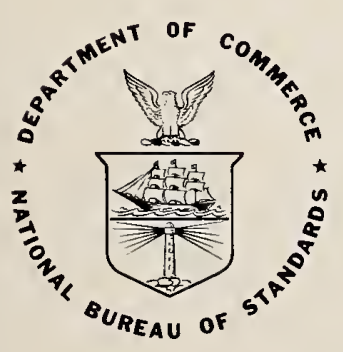

U.S. DEPARTMENT OF COMMERCE, Rogers C. B. Morton, Secretary James A. Baker, III, Under Secretary

Dr. Betsy Ancker-Johnson, Assistant Secretary for Science and Technology NATIONAL BUREAU OF STANDARDS, Ernest Ambler, Acting Director 


\section{National Bureau of Standards Special Publication 432}

(Supersedes NBS Special Publication 236, 1974 and previous editions)

Nat. Bur. Stand. (U.S.), Spec. Publ. 432, 20 pages (Jan. 1976)

CODEN: XNBSAV 


\section{FOREWORD}

This publication presents a description of the time and frequency dissemination services of the National Bureau of Standards. Those interested in information on the NBS atomic clock system, transmitting antennas, or discussion of technological applications of the dissemination services should refer to Section 8, Other Publications.

This SPECIAL PUBLICATION 432 replaces former Special Publication 236. It will be revised and reissued only as necessary to update information. 


\section{Contents}

Page

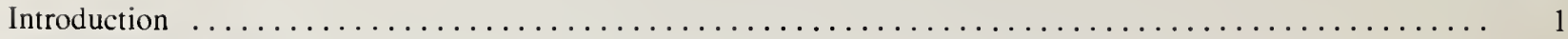

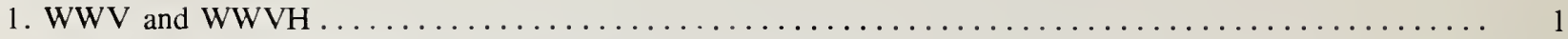

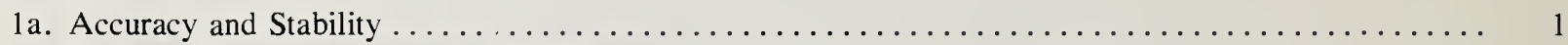

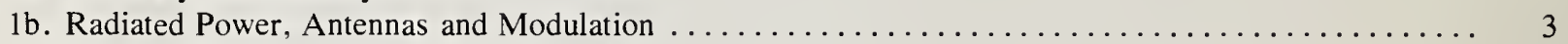

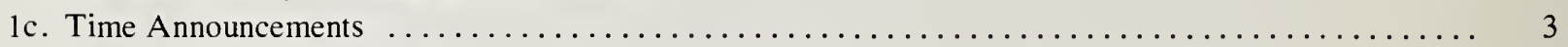

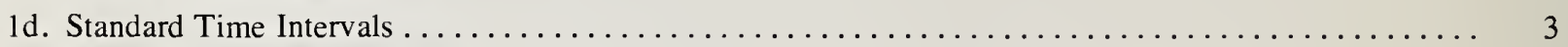

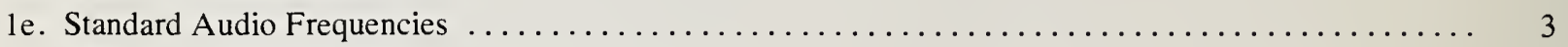

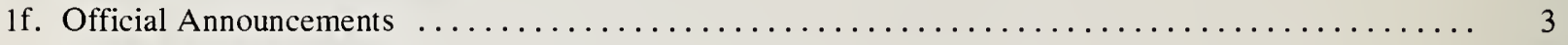

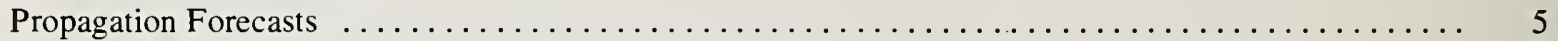

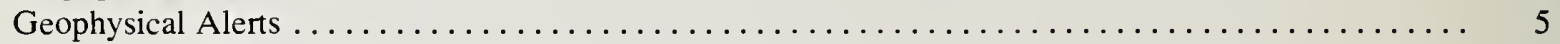

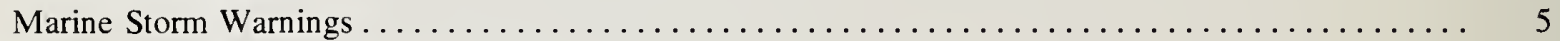

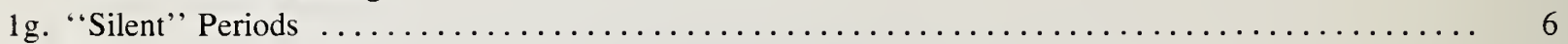

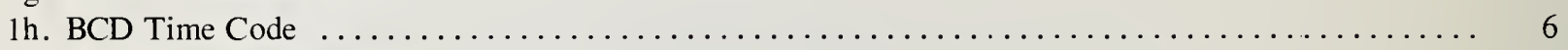

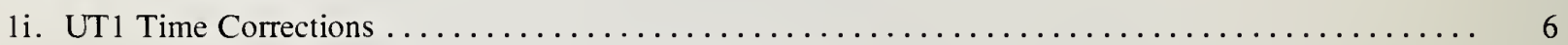

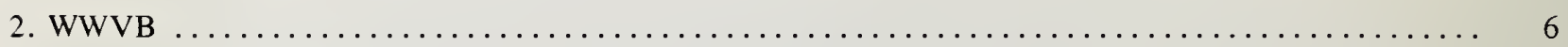

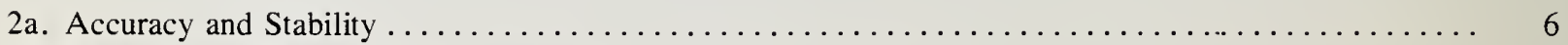

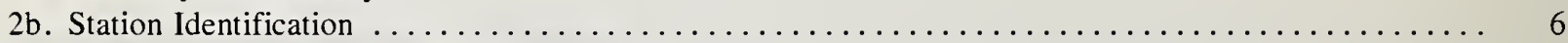

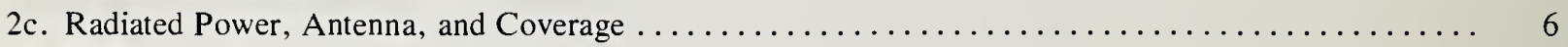

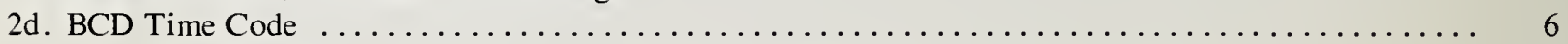

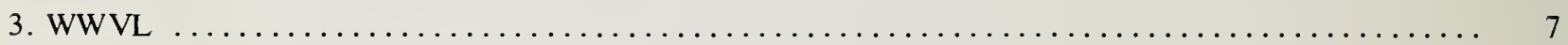

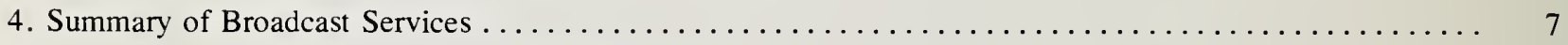

5. How NBS Controls the Transmitted Frequencies $\ldots \ldots \ldots \ldots \ldots \ldots \ldots \ldots \ldots \ldots \ldots \ldots \ldots \ldots \ldots$

6. Frequency Calibration Service Using Network Television $\ldots \ldots \ldots \ldots \ldots \ldots \ldots \ldots \ldots \ldots \ldots \ldots \ldots$

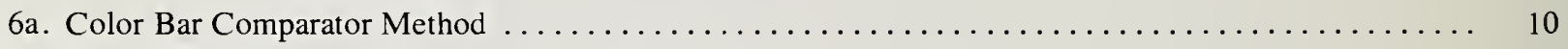

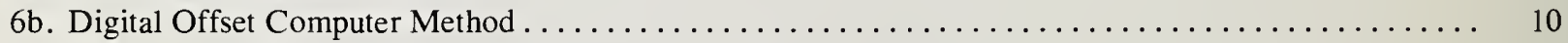

7. Time Comparisons Using Television Synchronization Pulses $\ldots \ldots \ldots \ldots \ldots \ldots \ldots \ldots \ldots \ldots \ldots \ldots$

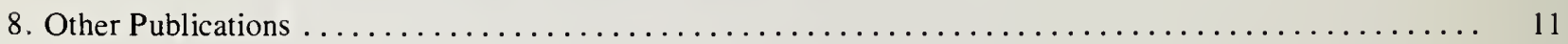

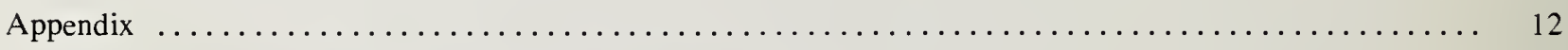

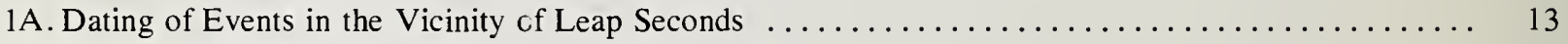

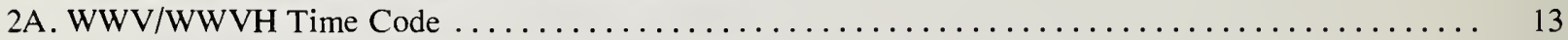

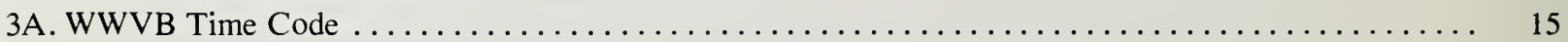




\title{
NBS Time and Frequency Dissemination Services
}

\author{
Sandra L. Howe
}

\begin{abstract}
Detailed descriptions are given of the time and frequency dissemination services of the National Bureau of Standards (NBS.) These services include the broadcasts from radio stations WWV, WWVH, WWVB, and WWVL (on an intermittent basis), and new time and frequency calibration services using television. This publication shows the services available on January 1, 1976. It will be updated only when the services are revised or when new services are added. A list of other publications available from the Time and Frequency Division of NBS is also included.
\end{abstract}

Key words: Broadcast of standard frequencies; frequency calibration; high frequency; low frequency; standard frequencies; television color subcarrier; time calibration; time signals.

\section{Introduction}

The time and frequency community is a small community, generally unknown to the world at large, yet vitally important to many of the basic activities of everyday living. Electric power companies, radio and television stations, telephone companies, and navigators of ships and planes all depend heavily on precise frequency and time information. They must have a constantly available source - a reliable, nationally and internationally recognized standard - with which to compare and regulate their own timing equipment. For over 50 years, the National Bureau of Standards (NBS) has been providing this standard for most users in the United States.*

Since the inception of the broadcast services from radio station WWV in 1923, NBS has continually improved and expanded its time and frequency dissemination services to meet the ever growing needs of an ever widening community of users. Today, still striving for better ways to serve its public, NBS is making major contributions to the nation's space and defense programs, to worldwide transportation and communications, and to a multitude of industrial operations, as well as providing convenient, highly accurate time service to many thousands of users throughout the world. Services are presently available from stations WWV and WWVB in Fort Collins, Colorado, and from WWVH in Kauai, Hawaii. In addition, new calibration services using network television are also available. This booklet is offered as a guide to these services.

\section{WWV and WWVH}

NBS broadcasts continuous signals from its highfrequency radio stations WWV and WWVH. The radio frequencies used are $2.5,5,10,15$, and $20 \mathrm{MHz}$. WWV also broadcasts on an additional frequency of $25 \mathrm{MHz}$.

*The U.S. Naval Observatory provides time standards for the Department of Defense and other interested users.
All frequencies carry the same program, but because of changes in ionospheric conditions, which sometimes adversely affect the signal transmissions, most receivers are not able to pick up the signal on all frequencies at all times in all locations. Except during times of severe magnetic disturbances, however-which make all radio transmissions almost impossible-listeners should be able to receive the signal on at least one of the broadcast frequencies. As a general rule, frequencies above $10 \mathrm{MHz}$ provide the best daytime reception while the lower frequencies are best for nighttime reception.

Services provided by these stations include:

\section{Time announcements \\ Standard time intervals \\ Standard frequencies \\ Propagation forecasts \\ Geophysical alerts \\ Marine storm warnings \\ UT1 time corrections \\ $B C D$ time code}

Figure 1 gives the hourly broadcast schedules of these services along with station location, radiated power, and details of the modulation.

\section{1a. Accuracy and Stability}

The time and frequency broadcasts are controlled by the primary NBS Frequency Standard in Boulder, Colorado. The frequencies as transmitted are accurate to within one part in 100 billion at all times. Deviations are normally less than one part in 1,000 billion from day to day. However, changes in the propagation medium (causing Doppler effect, diurnal shifts, etc.) result in fluctuations in the carrier frequencies as received by the user that may be very much greater than the uncertainty described above. 

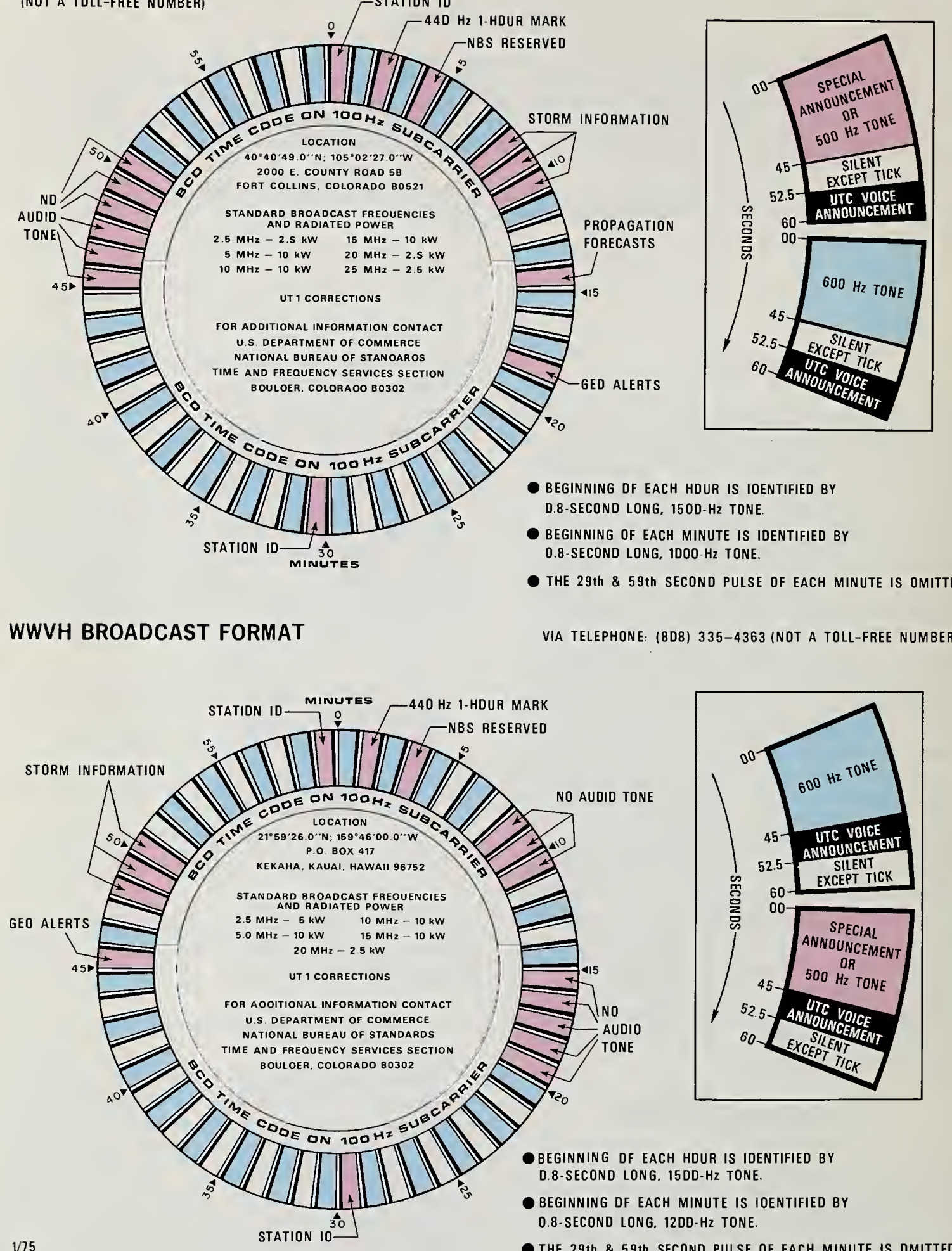

Figure 1. The hourly broadcast schedules of WWV and WWVH. 


\section{1b. Radiated Power, Antennas and Modulation}

\begin{tabular}{|c|c|c|}
\hline \multirow{2}{*}{$\begin{array}{c}\text { Frequency, } \\
\text { MHz }\end{array}$} & \multicolumn{2}{|c|}{ Radiated Power, kW } \\
\cline { 2 - 3 } & WWV & WWVH \\
\hline 2.5 & 2.5 & 5.0 \\
\hline 5.0 & 10.0 & 10.0 \\
\hline 10.0 & 10.0 & 10.0 \\
\hline 15.0 & 10.0 & 10.0 \\
\hline 20.0 & 2.5 & 2.5 \\
\hline 25.0 & 2.5 & - \\
\hline
\end{tabular}

The broadcasts on $5,10,15$, and $20 \mathrm{MHz}$ from WWVH are from phased vertical half-wave dipole arrays. They are designed and oriented to radiate a cardioid pattern directing maximum gain in a westerly direction. The $2.5 \mathrm{MHz}$ antenna at WWVH and all antennas at WWV are half-wave dipoles that radiate omnidirectional patterns.

At both WWV and WWVH, double sideband amplitude modulation is employed with 50 percent modulation on the steady tones, 25 percent for the BCD time code, 100 percent for seconds pulses, and 75 percent for voice.

\section{1c. Time Announcements}

Voice announcements are made from WWV and WWVH once every minute. To avoid confusion, a man's voice is used on WWV and a woman's voice on WWVH. The WWVH announcement occurs first - at 15 seconds before the minute-while the WWV announcement occurs at $7 \frac{1}{2}$ seconds before the minute. Though the announcements occur at different times, the tone markers referred to are transmitted simultaneously from both stations. However, they may not be received at the same time due to propagation effects.

The time referred to in the announcements is "Coordinated Universal Time" (UTC). It is coordinated through international agreements by the International Time Bureau (BIH) so that time signals broadcast from the many stations such as WWV throughout the world will be in close agreement.

The specific hour and minute mentioned is actually the time at the time zone centered around Greenwich, England, and may be considered generally equivalent to the more well-known "Greenwich Mean Time" (GMT). UTC time differs from your local time only by an integral number of hours. By knowing your own local time zone and using the chart of world time zones in figure 3 , the appropriate number of hours to add or subtract from UTC to obtain local time can be determined. The UTC time announcements are expressed in the 24-hour clock system -i.e., the hours are numbered beginning with 00 hours at midnight through 12 hours at noon to 23 hours, 59 minutes just before the next midnight.

\section{1d. Standard Time Intervals}

The most frequent sounds heard on WWV and WWVH are the pulses that mark the seconds of each minute, except for the 29th and 59th seconds pulses which are omitted completely. The first pulse of every hour is an 800 -millisecond pulse of $1500 \mathrm{~Hz}$. The first pulse of every minute is an 800 -millisecond pulse of $1000 \mathrm{~Hz}$ at WWV and $1200 \mathrm{~Hz}$ at WWVH. The remaining seconds pulses are brief audio bursts (5-millisecond pulses of $1000 \mathrm{~Hz}$ at WWV and $1200 \mathrm{~Hz}$ at WWVH) that resemble the ticking of a clock. All pulses commence at the beginning of each second. They are given by means of doublesideband amplitude modulation.

Each seconds pulse is preceded by 10 milliseconds of silence and followed by 25 milliseconds of silence to avoid interference which might make it difficult or impossible to pick out the seconds pulses. This total 40millisecond protected zone around each seconds pulse is illustrated in figure 2 .

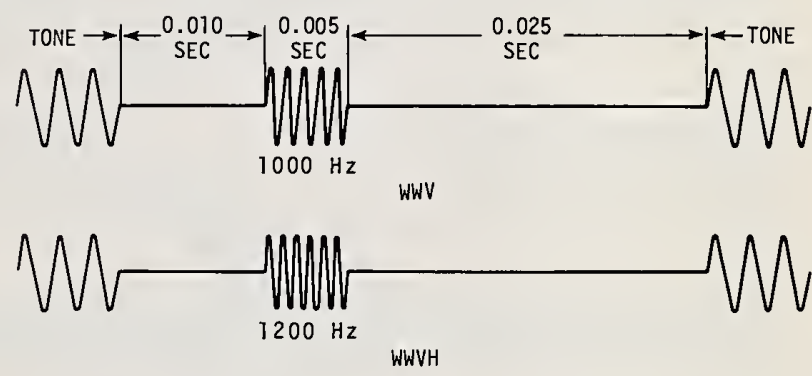

Figure 2. Format of WWV and WWVH seconds pulses.

\section{1e. Standard Audio Frequencies}

In alternate minutes during most of each hour, 500 or $600 \mathrm{~Hz}$ audio tones are broadcast. A $440 \mathrm{~Hz}$ tone, the musical note $\mathrm{A}$ above middle $\mathrm{C}$, is broadcast once each hour. In addition to being a musical standard, the $440 \mathrm{~Hz}$ tone can be used to provide an hourly marker for chart recorders or other automated devices.

\section{1f. Official Announcements}

Forty-five-second announcement segments (see fig. 1) are available on a subscription basis to other Federal agencies to disseminate official and public service information. The accuracy and content of these announcements are the responsibility of the originating agency, not necessarily NBS. 


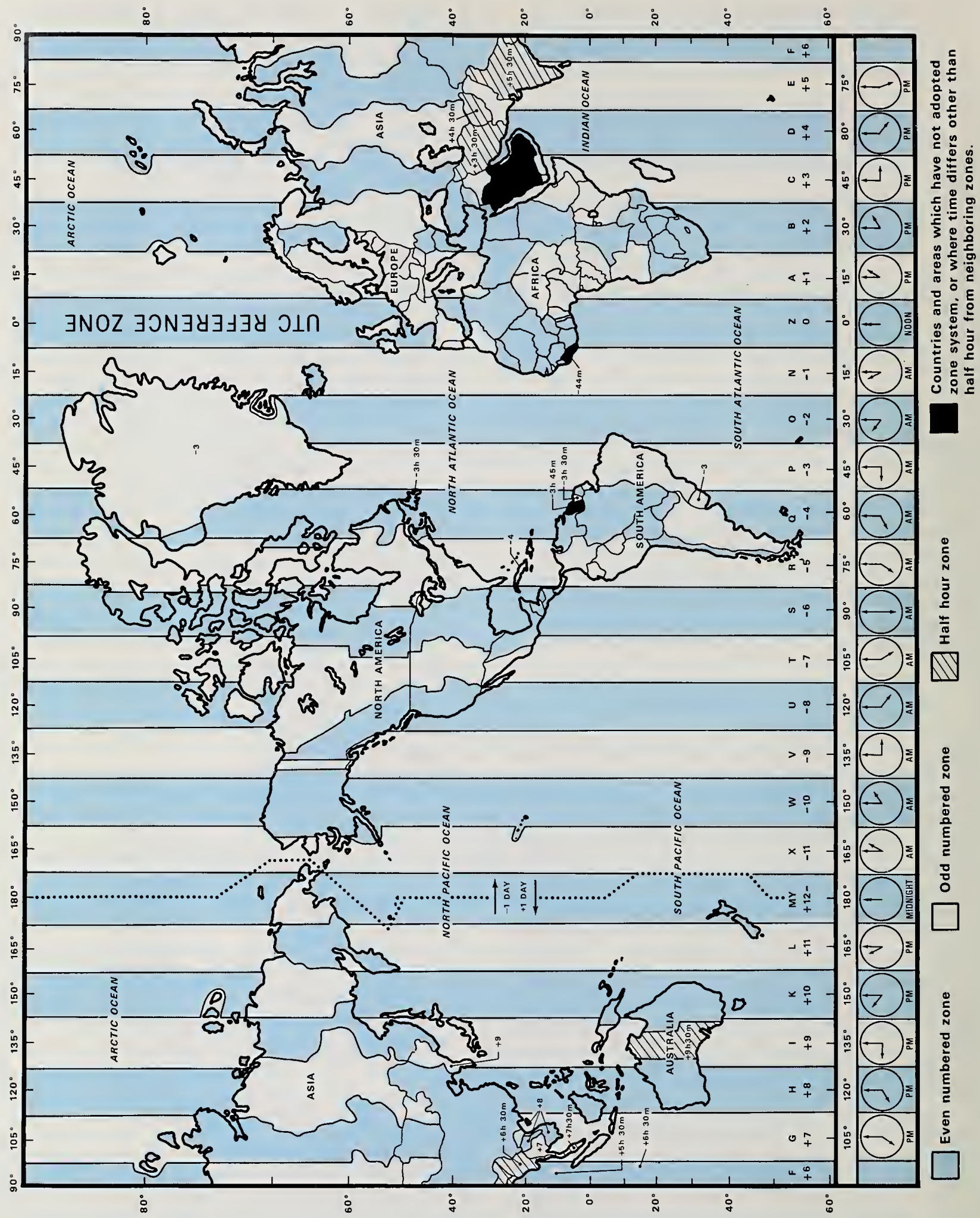

Figure 3. Standard time zones of the world and their relationship to UTC. 
Most segments except those reserved for NBS use and the semi-silent periods (see section $1 \mathrm{~g}$ ) are available. Arrangements for use of segments may be made through the Time and Frequency Services Section, 277.06, National Bureau of Standards, Boulder, CO 80302.

\section{Propagation Forecasts}

The propagation forecasts are given in voice at 14 minutes after each hour from WWV only. They are shortterm forecasts of propagation conditions along North Atlantic paths (such as Washington, D.C. to London or New York to Berlin) along with descriptions of current geomagnetic activity, $\mathrm{K}$-index values (a measure of the earth's magnetic field) and solar flux data (a measure of the overall level of solar activity). These forecasts are also applicable to high latitudes provided the appropriate time correction is made.

The propagation forecast announcements are given as a phonetic and a numeral. The phonetic identifies the radio propagation quality at the time the forecast is issued $(0100,0700,1300$, or 1900 UTC $)$. The numeral indicates the quality expected during the six-hour period after the forecast is issued. The meanings of the phonetics and numerals are:

Phonetic
Whiskey
Uniform
November

Numeral
One
Two
Three
Four
Five
Six
Seven
Eight
Nine

Meaning
Disturbed
Unsettled
Normal

Meaning

Useless

Very poor

Poor

Poor-to-fair

Fair

Fair-to-good

Good

Very good

Excellent

If, for example, propagation conditions are normal and expected to be good during the next six hours, the coded forecast announcement would be "November Seven."

The K-index is a measure of variation, or disturbance, in the earth's magnetic field during the three-hour period ending about one hour prior to issue of the forecast. The $\mathrm{K}$-figures range from 0 (very quiet) to 9 (extremely disturbed). The solar flux measurements are taken at 2800 $\mathrm{MHz}$ three times daily. The flux value is closely associated with the well-known daily sunspot number and is coming to be preferred to sunspot number as a measure of solar activity.
A typical announcement might be:

\begin{abstract}
"The radio propagation quality forecast at 0100 is good. Current geomagnetic activity is normal. The coded forecast is November Seven" (and then repeated). "The K-index at 0100 UTC is 2" (repeated), "tending to increase. The 2800 Megahertz solar flux index is 70 units" (repeated), "tending to remain constant."
\end{abstract}

The forecasts are prepared by the Telecommunications Services Center, Office of Telecommunications, Boulder, $\mathrm{CO} 80302$. Information regarding these forecasts may be obtained by writing to this address.

\section{Geophysical Alerts}

Current geophysical alerts (Geoalerts) are broadcast in voice from WWV at 18 minutes after each hour, and from WWVH at 45 minutes after each hour. The messages are changed daily at 0400 UTC with provisions to provide real-time data alerts of outstanding occurring events. These are followed by a summary of selected solar and geophysical events during the previous 24 hours. Inquiries regarding these messages should be addressed to the Space Environment Laboratory, National Oceanic and Atmospheric Administration, Boulder, CO 80302.

\section{Marine Storm Warnings}

Weather information about major storms in the Atlantic and eastern North Pacific are broadcast in voice from WWV at 8, 9, and 10 minutes after each hour. Similar storm warnings covering the eastern and central North Pacific are given from WWVH at 48, 49, and 50 minutes after each hour. An additional segment (at 11 minutes after the hour on WWV and at 51 minutes on WWVH) may be used when there are unusually widespread storm conditions. The brief messages are designed to tell mariners of storm threats in their areas. If there are no warnings in the designated areas, the broadcasts will so indicate. The ocean areas involved are those for which the U.S. has warning responsibility under international agreement. The regular times of issue by the National Weather Service are $0500,1100,1700$, and 2300 UTC for WWV and $0000,0600,1200$, and 1800 UTC for WWVH. These broadcasts are updated effective with the next scheduled announcement following the time of issue.

Mariners might expect to receive a broadcast similar to the following:

\footnotetext{
"North Atlantic weather West of 35 West at 1700 UTC: Hurricane Donna, intensifying, 24 North, 60 West, moving northwest, 20 knots, winds 75 knots; storm, 65 North, 35 West, moving east, 10 knots; winds 50 knots, seas 15 feet."
}

Information regarding these announcements may be obtained from the Director, National Weather Service, Silver Spring, MD 20910. 


\section{1g. "Silent" Periods}

These are periods with no tone modulation. However, the carrier frequency, seconds pulses, time announcements, and $100-\mathrm{Hz}$ BCD time code continue. The main silent periods extend from 45 to 51 minutes after the hour on WWV and from 15 to 20 minutes after the hour on WWVH. An additional 3-minute period from 8 to 11 minutes after the hour is silent on WWVH.

\section{1h. BCD Time Code}

A binary coded decimal (BCD) time code is transmitted continuously by WWV and WWVH on a $100-\mathrm{Hz}$ subcarrier. The $100-\mathrm{Hz}$ subcarrier is synchronous with the code pulses so that 10 -millisecond resolution is attained. The time code provides a standard timing base for scientific observations made simultaneously at different locations. It has application, for example, where signals telemetered from a satellite are recorded along with the time code pulses. Data analysis is then aided by having accurate, unambiguous time markers superimposed directly on the recording.

The WWV/WWVH time code format presents UTC information in serial fashion at a rate of one pulse per second. Groups of pulses can be decoded to ascertain the current minute, hour, and day of year. While the $100-\mathrm{Hz}$ subcarrier is not considered one of the standard audio frequencies, the code does contain the $100-\mathrm{Hz}$ frequency and may be used as a standard with the same accuracy as the audio frequencies. A description of the time code is contained in the Appendix.

\section{1i. UT1 Time Corrections}

The UTC time scale broadcast by WWV and WWVH runs at a rate that is almost perfectly constant because it is based on ultra-stable atomic clocks. This time scale meets the needs of most users. Somewhat surprisingly, however, some users of time signals need time which is not this stable. In applications such as very precise navigation and satellite tracking, which must be referenced to the rotating earth, a time scale that speeds up and slows down with the earth's rotation rate must be used. The particular time scale needed is known as UT1 and is inferred from astronomical observations.

To be responsive to these users, information needed to obtain UT 1 time is included in the UTC broadcasts. This occurs at two different levels of accuracy. First, for those users needing to know UT1 only to within about one second (this includes nearly all boaters/navigators), occasional corrections of exactly one second-called "leap" seconds - are inserted into the UTC time scale whenever needed to keep the UTC time signals within \pm 0.9 second of UT1 at all times. These leap seconds may be either positive or negative and are coordinated under international agreement by the International Time Bureau (BIH) in Paris. Ordinarily, a positive leap second must be added about once per year (usually on June 30 or December 31 ), depending on how the earth's rotation rate is behaving in each particular year. Information on how to assign dates to events that occur near the time of a leap second insertion is given in the Appendix.

The second level of correction is included in the UTC broadcasts for the very small number of users who need UT 1 time to better than one second. These corrections, in units of 0.1 second, are encoded into the broadcasts by using double ticks or pulses after the start of each minute. The amount of correction is determined by counting the number of successive double ticks heard each minute. The 1 st through the 8th seconds ticks indicate a "plus" correction, and the 9th through the 16th, a "minus" correction. For example, if the $1 \mathrm{st}, 2 \mathrm{nd}$, and 3 rd ticks are doubled, the correction is "plus" 0.3 second: UT1 $1=$ UTC +0.3 second, or if UTC is $8: 45: 17$, then UT 1 is $8: 45: 17.3$. If the 9 th, 10 th, 11 th, and 12 th ticks are doubled, the correction is "minus" 0.4 second, or as in the above example, UT $1=8: 45: 16.6$.

\section{WWVB}

WWVB transmits continuously on a standard radio carrier frequency of $60 \mathrm{kHz}$. Standard time signals, time intervals, and UT 1 corrections are provided by means of a $\mathrm{BCD}$ time code. The station is located on the same site as WWV. Effective coverage area is the continental U.S.

\section{2a. Accuracy and Stability}

The frequency of WWVB is normally within its prescribed value to better than 1 part in 100 billion. Deviations from day to day are less than 5 parts in 1,000 billion. Effects of the propagation medium on received signals are relatively minor at low frequencies; therefore, frequency comparisons to better than 1 part in 100 billion are possible using appropriate receiving and averaging techniques .

\section{2b. Station Identification}

WWVB identifies itself by advancing its carrier phase $45^{\circ}$ at 10 minutes after every hour and returning to normal phase at 15 minutes after the hour. WWVB can also be identified by its unique time code.

\section{2c. Radiated Power, Antenna, and Coverage}

The effective radiated power from WWVB is $13 \mathrm{~kW}$. The antenna is a 122-meter, top-loaded vertical installed over a radial ground screen. Some measured field intensity contours are shown in figure 4.

\section{2d. BCD Time Code}

WWVB broadcasts time information in the form of a 


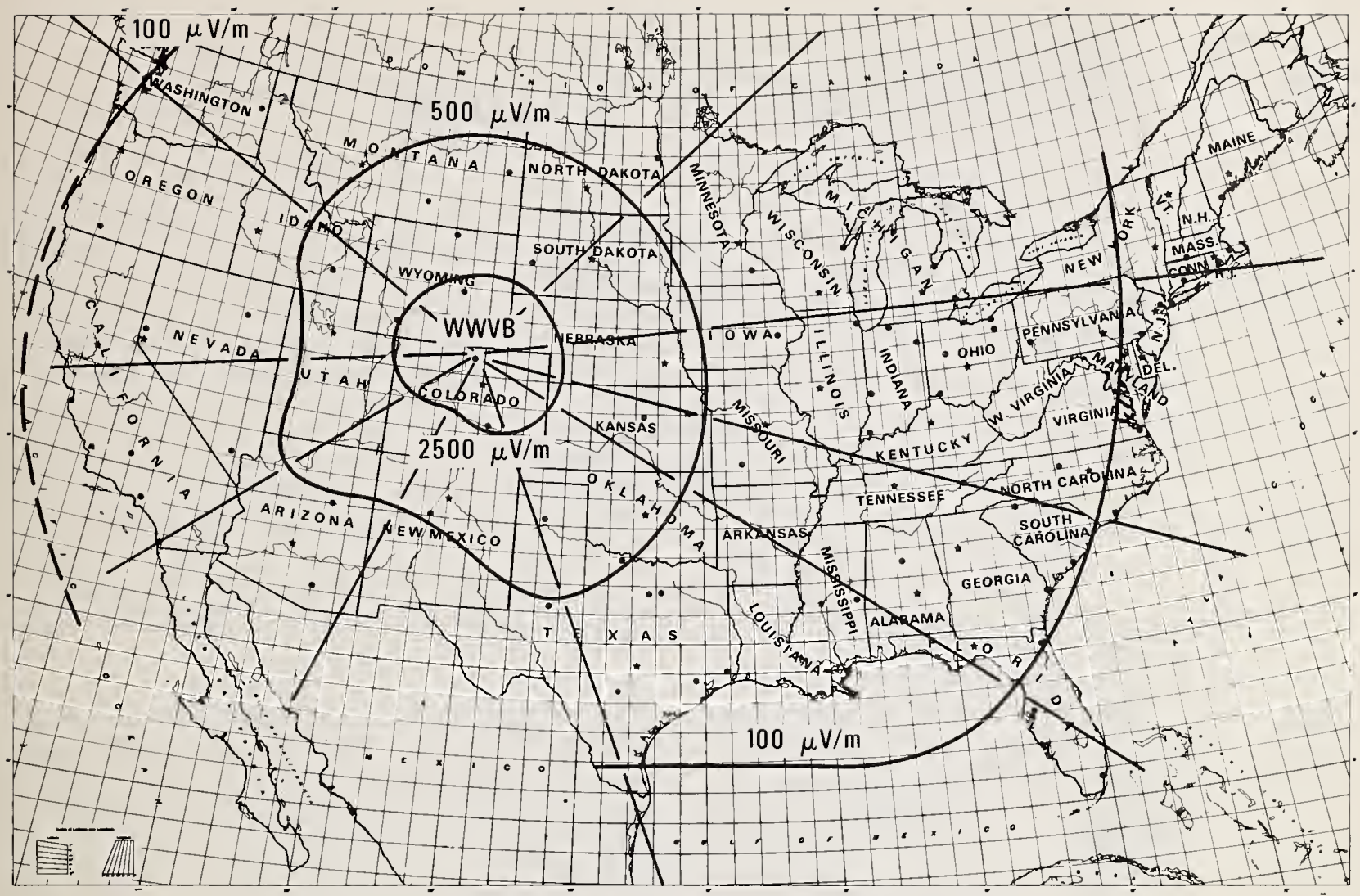

Figure 4. Measured field intensity countours of WWVB at $13 \mathrm{~kW}$ ERP

BCD time code. The time code is synchronized with the $60-\mathrm{kHz}$ carrier and is broadcast continuously at a rate of one pulse per second. Each pulse is generated by reducing the carrier power $10 \mathrm{~dB}$ at the beginning of the second, so the leading edge of every negative-going pulse is on time. Details of the WWVB time code are presented in the Appendix.

\section{WWVL}

WWVL is an experimental station. Regular operations were curtailed on July 1, 1972, and it now broadcasts experimental programs only on an intermittent basis, depending upon need and availability of funds. Transmissions can be made available on a subscription basis to public organizations and other Federal agencies. Arrangements for use should be made through the Time and Frequency Services Section, National Bureau of Standards, Boulder, CO 80302.

\section{Summary of Broadcast Services}

The services provided by the NBS radio stations are summarized in the following chart. Coordinates for the stations are also listed.

\begin{tabular}{|c|c|c|c|c|c|c|c|c|}
\hline 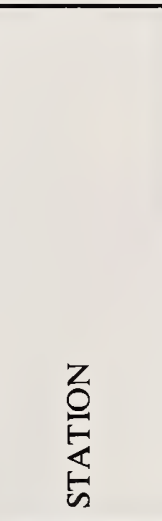 & 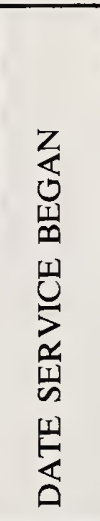 & 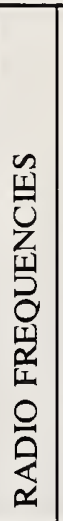 & 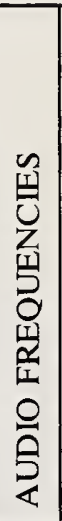 & 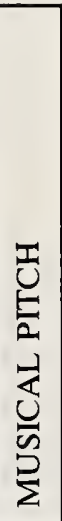 & 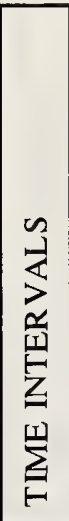 & 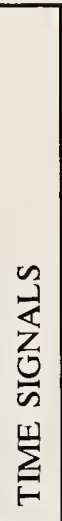 & 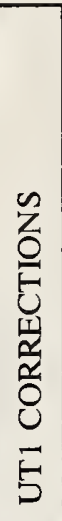 & 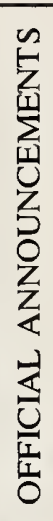 \\
\hline WWV & 1923 & $\mathrm{X}$ & $\mathrm{X}$ & $\mathrm{X}$ & $\mathrm{X}$ & $\mathrm{X}$ & $\mathrm{X}$ & $\mathrm{X}$ \\
\hline WWVH & 1948 & $\mathrm{X}$ & $\mathrm{X}$ & $\mathrm{X}$ & $\mathrm{X}$ & $\mathrm{X}$ & $\mathrm{X}$ & $\mathrm{X}$ \\
\hline WWVB & 1956 & $\mathrm{X}$ & & & $\mathrm{X}$ & $\mathrm{X}$ & $\mathrm{X}$ & \\
\hline WWVL & 1960 & $\mathrm{X}$ & & & & & & \\
\hline \multicolumn{9}{|c|}{ COORDINATES: } \\
\hline WWV & \multicolumn{3}{|c|}{$40^{\circ} 40^{\prime} 49.0^{\prime \prime} \mathrm{N}$} & \multicolumn{5}{|c|}{$105^{\circ} 02^{\prime} 27.0^{\prime \prime} \mathrm{W}$} \\
\hline WWVB & \multicolumn{3}{|c|}{$40^{\circ} 40^{\prime} 28.3^{\prime}, \mathrm{N}$} & \multicolumn{5}{|c|}{$105^{\circ} 02^{\prime} 39.5^{\prime \prime} \mathrm{W}$} \\
\hline WWVL & \multicolumn{3}{|c|}{$40^{\circ} 40^{\prime} 51.3^{\prime \prime} \mathrm{N}$} & \multicolumn{5}{|c|}{$105^{\circ} 03^{\prime} 00.0^{\prime \prime} \mathrm{W}$} \\
\hline WWVH & \multicolumn{3}{|c|}{$21^{\circ} 59^{\prime} 26.0^{\prime \prime} \mathrm{N}$} & \multicolumn{5}{|c|}{$159^{\circ} 46^{\prime} 00.0^{\prime \prime} \mathrm{W}$} \\
\hline
\end{tabular}




\section{NATIONAL BUREAU OF STANDARDS FREQUENCY AND TIME FACILITIES}

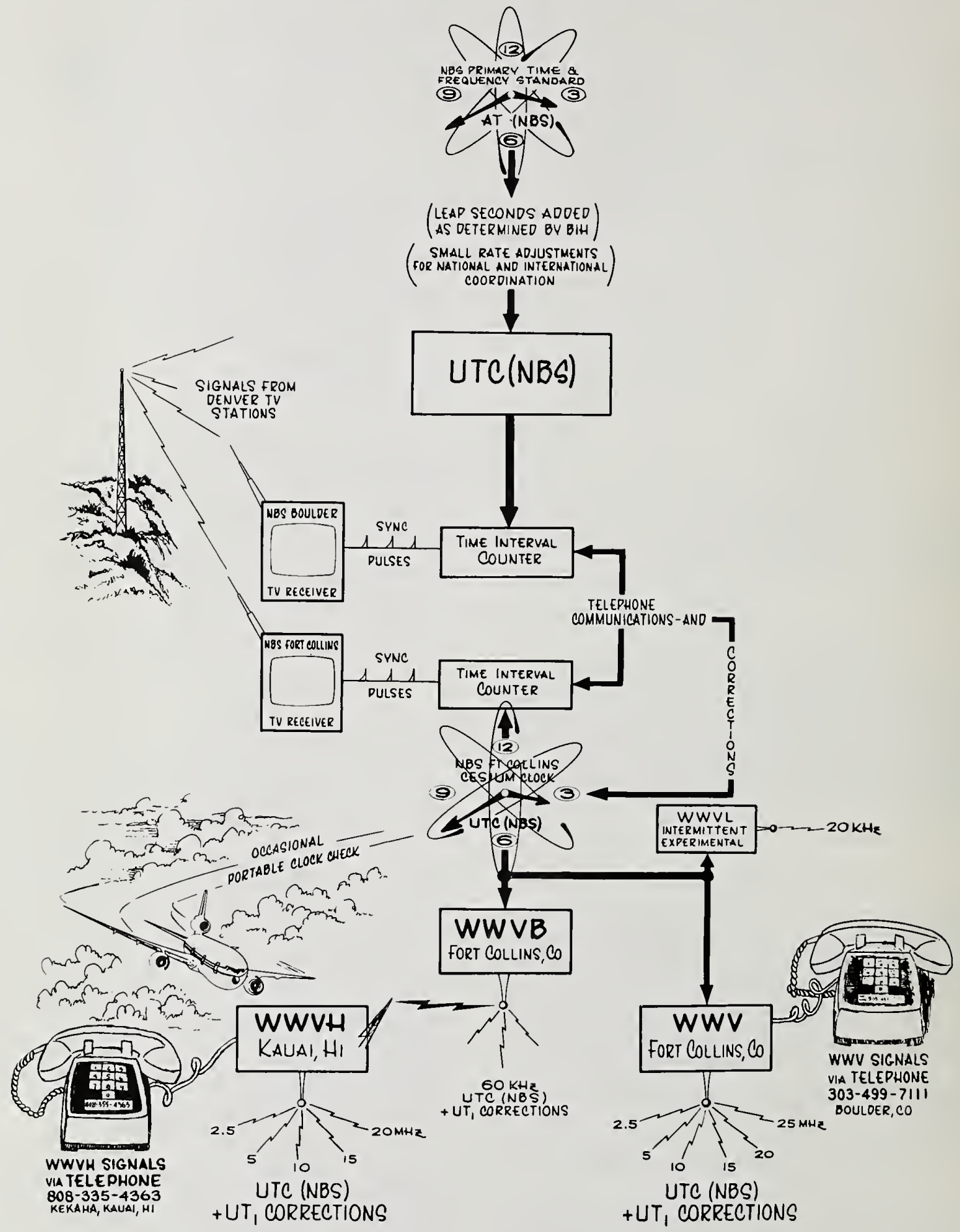

Figure 5. The NBS frequency control system. 


\section{How NBS Controls the Transmitted Frequencies}

A simplified diagram of the NBS frequency control system is shown in figure 5 . The entire system depends upon the reference shown in this diagram as the NBS Primary Time and Frequency Standard. This standard is comprised of a number of commercial cesium beam clocks, up to two primary cesium beam frequency and time standards, and computer-aided measurement and computation methods which combine all of the clock data to generate an accurate and uniform time scale, AT (NBS). Another scale, UTC (NBS), is also generated by adding leap seconds and small corrections to AT (NBS) as needed to keep UTC (NBS) synchronized with the internationally coordinated time scale, UTC, which is maintained by the BIH.

Utilizing the line-10 horizontal synchronizing pulses from a local television station, the Fort Collins master clock is compared on a regular basis with the UTC (NBS) time scale. All other clocks and time-code generators at the Fort Collins site are then compared with the Fort Collins master clock. Frequency corrections of the WWVB and WWVL quartz crystal oscillators are based on their phase relative to the UTC (NBS) time scale.
The transmissions from WWV and WWVH are controlled by three commercial cesium standards located at each site. To insure accurate time transmission from each station, the time-code generators are compared with the stations' master clock several times each day.

Control of the signals transmitted from WWVH is based not only upon the cesium standards, but upon signals from WWVB as received by phase-lock receivers. The cesium standards controlling the transmitted frequencies and time signals are continuously compared with the received signals.

To insure that systematic errors do not enter into the system, the UTC (NBS) time scale is occasionally compared with the transmitting station clocks by the use of a very precise portable atomic clock.

\section{Frequency Calibration Service Using Network Television}

For those users who require only frequency calibrations, an alternative to the radio broadcasts is available. This new service provides a means of calibrating oscillators traceable to NBS. It gives the user the option of calibrating his oscillator quickly at very low cost with modest accuracy or of expending more time and money for higher accuracy.

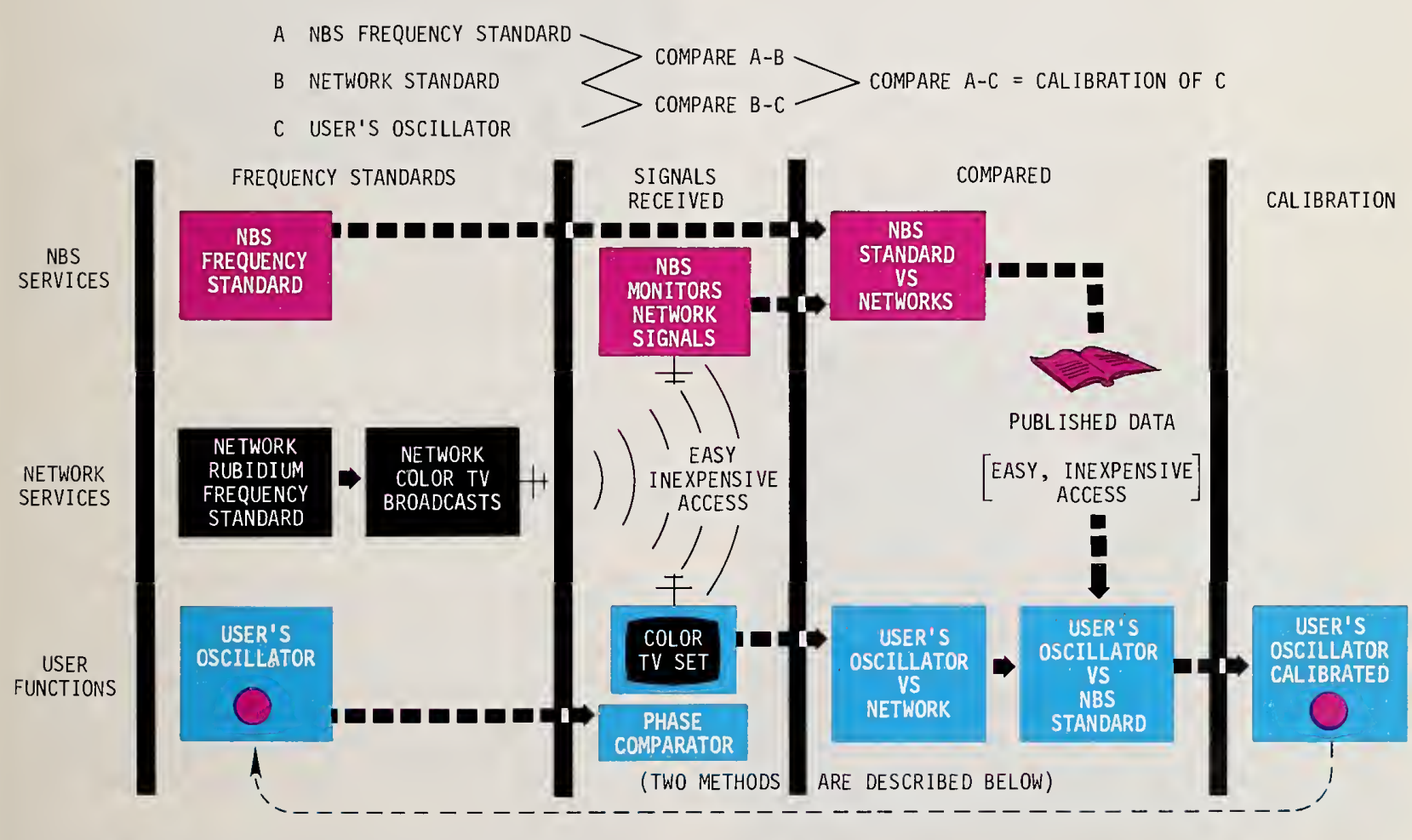

Figure 6. How the frequency calibration service using color television works. 
The service is very reliable because the networks use extremely stable rubidium oscillators to generate the $\mathbf{3 . 5 8}$ $\mathrm{MHz}$ color subcarrier frequency which is transmitted with all color programs. The color signal is then used as a transfer standard. Any oscillator that has a frequency of $10 / \mathrm{N} \mathrm{MHz}$, where $\mathrm{N}$ is any integer from 1 to 100 , can be calibrated.

If a user wants to make a calibration, he compares the color signal coming from the network centers in New York City (or Los Angeles for those on the West Coast) with his local oscillator. NBS monitors the same network signals and publishes the difference between the network oscillators and the NBS Frequency Standard in the monthly NBS Time and Frequency Services Bulletin. A user then knows two things: (1) the difference between his oscillator and the network oscillators (by measurement) and (2) the difference between the networks and NBS (by publication). With this information, he can easily compute the difference between his oscillator and NBS (see fig. 6). Thus, his calibration is traceable to the NBS Frequency Standard.

NBS has developed two methods for making these frequency calibrations. Equipment is commercially available for both methods.

\section{6a. Color Bar Comparator Method}

The color bar comparator is a simple circuit that connects to a standard color television set (fig.7). It produces a colored bar on the screen that changes color or moves across the screen at a rate that depends on the frequency difference between the user's oscillator and the TV network signal. By timing these changes with a stopwatch and referring to the data published by NBS, an oscillator can be rapidly calibrated to an accuracy of 1 part in 1 billion.

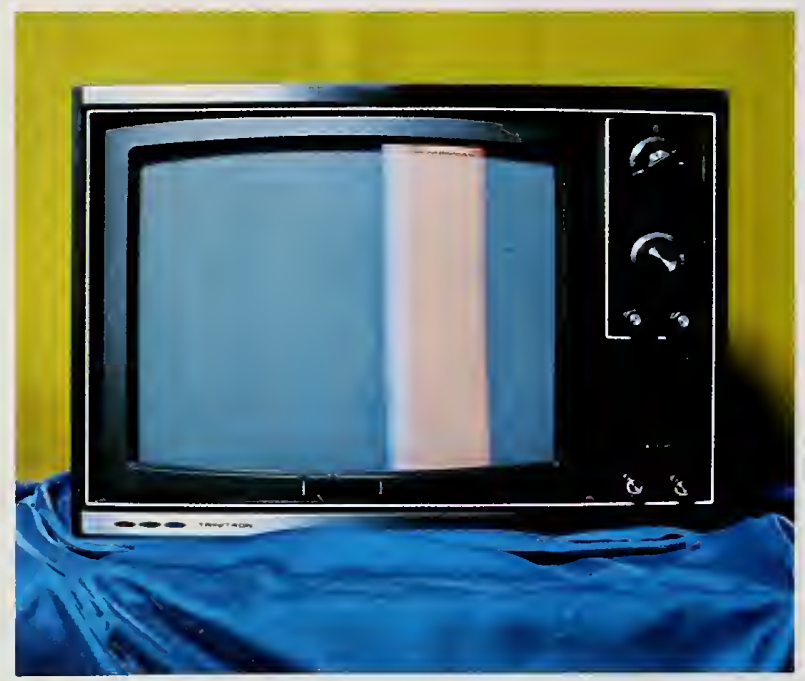

Figure 7. Prototype of a color bar comparator.

\section{6b. Digital Offset Computer Method}

The second method, using a digital of fset computer, provides an automatic means of calibrating high-quality crystal or atomic oscillators. It compares a signal from the user's oscillator with the TV color signal and displays the frequency difference on the TV screen (fig.8) as parts in 100 billion. If the measurements are averaged over about 15 minutes, a calibration accuracy of one part in 100 billion can usually be achieved.

More information on this service, including circuit details and lists of equipment manufacturers, is available upon request from the Time and Frequency Services Section, NBS, Boulder, CO 80302.

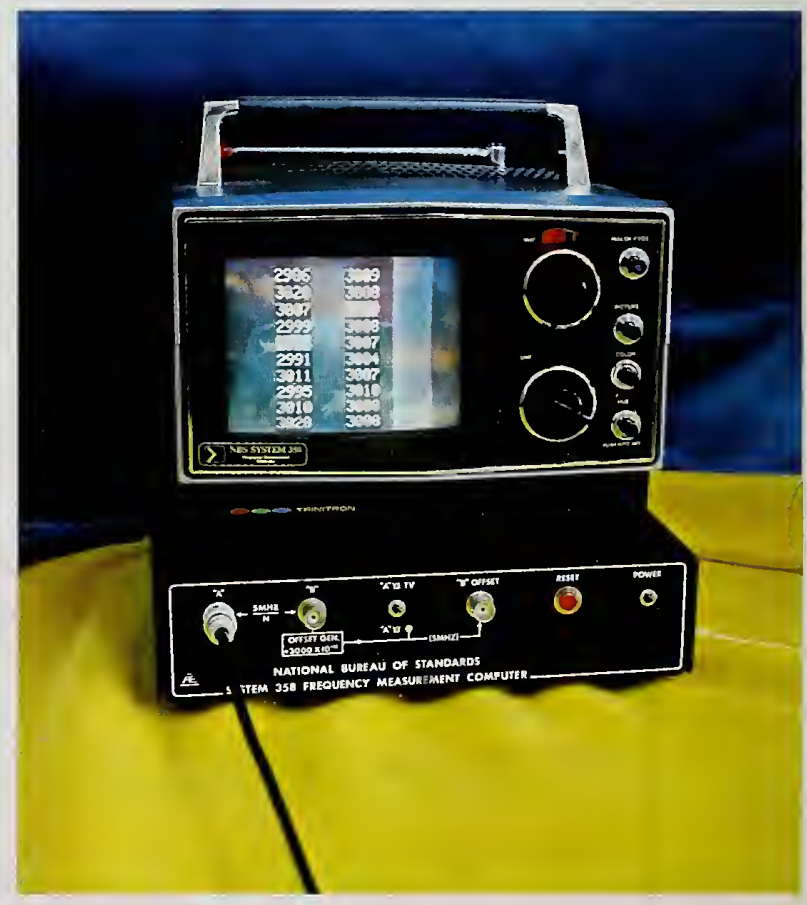

Figure 8. Prototype of a digital offset computer.

\section{Time Comparisons Using Television Synchronization Pulses}

In the previous section, methods were described for using the frequency of a network television signal as a transfer standard to link the user to the NBS Frequency Standard. In a similar way, it is also possible to use a particular synchronization pulse present in the normal television picture signal as a time transfer standard to allow clock comparisons to be made with the UTC (NBS) atomic time scale.

To use this technique, a user first makes a simple time difference measurement at a specified time during the day between his local clock and a particular television signal 
pulse (line-10 (odd) horizontal synchronization pulse) obtained from a normal television receiver. Commercial equipment is available which can be used for this purpose. NBS also measures, at the same specified time, the time difference between the TV synchronization pulse as received in Boulder, Colorado and the UTC (NBS) time scale and publishes the data in the monthlyNBS Time and Frequency Services Bulletin. The difference between the local measurement and the published NBS measurement then represents the time difference between the user's clock and UTC (NBS) plus a propagation delay.

If the propagation delay can be determined - for example, by a portable clock measurement, then this part of the measurement can be subtracted out, leaving only the actual time difference between the local and NBS clocks. Although the propagation delay of the TV signals through the nationwide TV network distribution system has been shown to be relatively constant to within a few microseconds for long periods extending over weeks or months, occasional large changes of many milliseconds do occur due to network rerouting of TV signals. These large changes are usually easy to recognize, especially if a user regularly monitors more than one of the major TV networks.

Even if the propagation delays are not measured or otherwise determined, the line-10 technique can still provide useful information about the stability performance of a user's time scale or clock relative to NBS. As long as the delay remains constant, daily line-10 comparisons will show whether a user's clock is gaining or losing time relative to NBS, even though the exact time difference cannot be determined without knowing the value for the propagation delay.

NBS publishes daily line-10 measurements for all three major television networks and for both East Coast and West Coast-originated transmissions. The West Coast data are suppied by the Hewlett-Packard Co. in Santa Clara, California and are referenced to UTC (NBS) with an accuracy of about 0.5 microsecond. West Coast data is for use only by those users in the Pacific Time Zone. For current specific times during the day when each network is measured, potential users of the line-10 time transfer technique should either consult a current issue of the NBS Time and Frequency Services Bulletin or contact the Time and Frequency Services Section, NBS, Boulder, CO 80302 .

\section{Other Publications}

The Time and Frequency Division offers a variety of publications about the NBS atomic time and frequency standards, the associated dissemination services and how to use them. These publications are available upon request.

For information about the atomic clock, primary time and frequency standard, as well as special time and frequency calibration, test, and measurement services, write to the Frequency and Time Standards Section, NBS, Boulder, CO 80302 or call (303) 499-1000, x 3276. The following are available:

\section{General Information}

Frequency Standards and Clocks: A Tutorial Introduction, Helmut Hellwig, Nat. Bur. Stand. (U.S.), Tech. Note 616, 69 pages, Revised (March 1974).

\section{Technical Publications}

Accuracy Evaluation and Stability of the NBS Primary Frequency Standards, D. J. Glaze, H. Hellwig, et al, IEEE Trans. on Instr. \& Meas., Vol. IM-23, No. 4 (Dec. 1974).

Atomic Frequency Standards: A Survey, H. Hellwig, Proc. IEEE, Vol. 63, No. 2 (Feb. 1975).

Time and Frequency, H. Hellwig, D.W. Allan, F.L. Walls, Proc. 5th Intl. Conf. on Atomic Masses and Fundamental Constants (AMCO-5), Paris, France (June 2-6, 1975).

An Accurate Algorithm for an Atomic Time Scale, D. W. Allan, H. Hellwig, D. J. Glaze, Metrologia, Vol. 11, (1975).

For more detailed technical information on how to use the time and frequency dissemination services, the following publications are available from the Time \& Frequency Services Section, NBS, Boulder, CO 80302 (Phone (303) 499-1000, x3212):

Frequency Standard Hides in Every Color TV Set, D. Davis, Electronics (May 10, 1971).

Calibrating Crystal Oscillators with TV Color-refererence Signals, D. Davis, Electronics (March 20, 1975).

The Use of NBS High Frequency Broadcasts for Time \& Frequency Calibrations, N. Hironaka and C. Trembath, Nat. Bur. Stand. (U.S.), Tech. Note 668 (May 1975).

Characterization and Concepts of Time-Frequency Dissemination, J. L. Jespersen, B.E.Blair, and L.E. Gatterer, Proc. IEEE, Vol. 60, No. 5, May 1972. 


\section{Appendix}

1A. Dating of Events in the Vicinity of Leap Seconds

2A. WWV/WWVH Time Code

3A. WWVB Time Code 


\section{A Dating of Events in the Vicinity of Leap Seconds}

When leap second adjustments are necessary to keep the broadcast time signals (UTC) within \pm 0.9 second of the earth-related UT 1 time scale, the addition or deletion of exactly 1 second occurs at the end of the UTC month. By international agreement, first preference is given to December 31 or June 30 , second preference to March 31 or September 30, and third preference to any other month.

When a positive leap second is required - that is, when UT1 is slow relative to UTC - an additional second is inserted beginning at $23 \mathrm{~h} 59 \mathrm{~m} 60 \mathrm{~s}$ of the last day of the month and ending at $\not \mathrm{h} g \mathrm{~m}$ g $/ \mathrm{s}$ of the first day of the following month. In this case, the last minute of the month in which there is a leap second contains 61 seconds. To assign dates to events which occur around this extra second, refer to figure $1 \mathrm{~A}$.

\section{NORMAL MINUTE}

(NO LEAP SECOND ADDED)

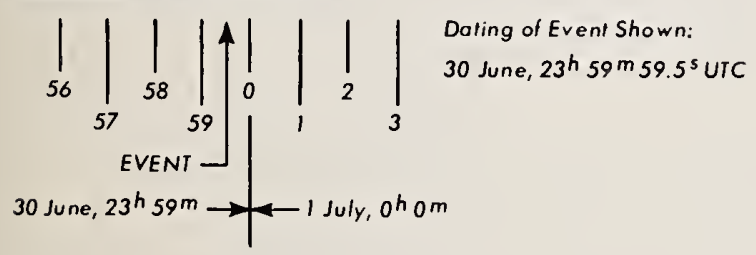

MINUTE WITH LEAP SECOND ADDED

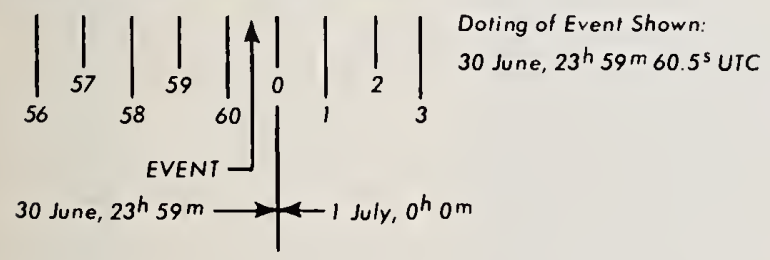

Figure 1A. Dating of events in the vicinity of a leap second.

Assuming that unexpected large changes do not occur in the earth's rotation rate in the future, it is likely that positive leap seconds will continue to be needed about once per year. If, however, the earth should speed up significantly at some future time, so that UT 1 runs at a faster rate than UTC, then provision is also made for negative leap seconds in the UTC time scale. In this case, exactly one second would be deleted at the end of some UTC month, and the last minute would contain only 59 seconds.

Positive leap seconds were inserted in all NBS broadcasts at the end of June 1972, December 1972, December 1973. December 1974, and December 1975.

\section{A. WWV/WWVH Time Code}

The WWV/WWVH time code is a modified version of the IRIG-H format. Data is broadcast on a $100-\mathrm{Hz}$ subcarrier at a rate of one pulse per second. Certain pulses in succession comprise binary-coded groups representing decimal numbers. The binary-to-decimal weighting scheme is $1-2-4-8$ with the least significant binary digit always transmitted first. The binary groups and their basic decimal equivalents are shown in the following table:

\begin{tabular}{|c|c|c|}
\hline Weight: & $\begin{array}{c}\text { BINARY GROUP } \\
1248 \\
\end{array}$ & $\begin{array}{c}\text { DECIMAL } \\
\text { EQU1VALENT }\end{array}$ \\
\hline & 00000 & 0 \\
\hline & 1000 & 1 \\
\hline & $\begin{array}{llll}0 & 1 & 0 & 0\end{array}$ & 2 \\
\hline & 1100 & 3 \\
\hline & $\begin{array}{llll}0 & 0 & 1 & 0\end{array}$ & 4 \\
\hline & $\begin{array}{llll}1 & 0 & 1 & 0\end{array}$ & 5 \\
\hline & $\begin{array}{llll}0 & 1 & 1 & 0\end{array}$ & 6 \\
\hline & 1110 & 7 \\
\hline & $\begin{array}{llll}0 & 0 & 0 & 1\end{array}$ & 8 \\
\hline & $\begin{array}{llll}1 & 0 & 0 & 1\end{array}$ & 9 \\
\hline
\end{tabular}

In every case, the decimal equivalent of a BCD group is derived by multiplying each binary digit times the weight factor of its respective column and then adding the four products together. For instance, the binary sequence 1010 in the 1-2-4-8 scheme means $(1 \times 1)+(0 \times 2)+(1 \times 4)$ $+(0 \times 8)=1+0+4+0=5$, as shown in the table. If fewer than nine decimal digits are needed, one or more of the binary columns may be omitted.

In the standard IRIG-H code, a binary 0 pulse consists of exactly 20 cycles of $100-\mathrm{Hz}$ amplitude modulation (200 milliseconds duration), whereas a binary 1 consists of 50 cycles of $100 \mathrm{~Hz}$ (500 milliseconds duration). In the WWV/WWVH broadcast format, however, all tones are suppressed briefly while the seconds pulses are transmitted (see sec. 1c).

Because the tone suppression applies also to the $100-\mathrm{Hz}$ subcarrier frequency, it has the effect of deleting the first 30 -millisecond portion of each binary pulse in the time code. Thus, a binary 0 contains only 17 cycles of $100-\mathrm{Hz}$ amplitude modulation (170 milliseconds duration) and a binary 1 contains 47 cycles of $100 \mathrm{~Hz}$ (470 milliseconds duration). The leading edge of every pulse coincides with a positive-going zero crossing of the $100-\mathrm{Hz}$ subcarrier, but it occurs 30 milliseconds after the beginning of the second.

Within a time frame of one minute, enough pulses are transmitted to convey in $\mathrm{BCD}$ language the current minute, hour, and day of year. Two BCD groups are needed to express the hour (00 through 23 ); and three groups are needed to express the day of year (001 through 366 ). When representing units, tens, or hundreds, the basic $1-2-4-8$ weights are simply multiplied by 1,10 , or 100 as 
appropriate. The coded information always refers to time at the beginning of the one-minute frame. Seconds may be determined by counting pulses within the frame.

Each frame commences with a unique spacing of pulses to mark the beginning of a new minute. No pulse is transmitted during the first second of the minute. Instead, a one-second space or hole occurs in the pulse train at that time. Because all pulses in the time code are 30 milliseconds late with respect to UTC, each minute actually begins 1030 milliseconds (or 1.03 seconds) prior to the leading edge of the first pulse in the new frame.

For synchronization purposes, every ten seconds a socalled position identifier pulse is transmitted. Unlike the BCD data pulses, the position identifiers consist of 77 cycles of $100 \mathrm{~Hz}$ (770 milliseconds duration).

UT 1 corrections to the nearest 0.1 second are broadcast via $B C D$ pulses during the final ten seconds of each frame. The coded pulses which occur between the 50th and 59th seconds of each frame are called control functions. Control function \# 1 , which occurs at 50 seconds, tells whether the UT 1 correction is negative or positive. If control function \#1 is a binary 0 , the correction is negative; if it is a binary 1 , the correction is positive. Control functions \#7, \#8, and \#9, which occur respectively at 56,57 , and 58 seconds, specify the amount of UT1 correction. Because the UT 1 corrections are expressed in tenths of a second, the basic binary-to-decimal weights are multiplied by 0.1 when applied to these control functions.

Control function \#6, which occurs at 55 seconds, is programmed as a binary 1 throughout those weeks when Daylight Saving Time is in effect and as a binary 0 when Standard Time is in effect. The setting of this function is changed at 0000 UTC on the date of change. Throughout the U.S. mainland, this schedule allows several hours for the function to be received before the change becomes effective locally-i.e., at 2:00 a.m. local time. Thus, control function \#6 allows clocks or digital recorders operating on local time to be programmed to make an automatic one-hour adjustment in changing from Daylight Saving Time to Standard Time and vice versa.

Figure 2A depicts one frame of the time code as it might appear after being rectified, filtered, and recorded. In this example, the leading edge of each pulse is considered to be the positive-going excursion. The pulse train in the figure is annotated to show the characteristic features of

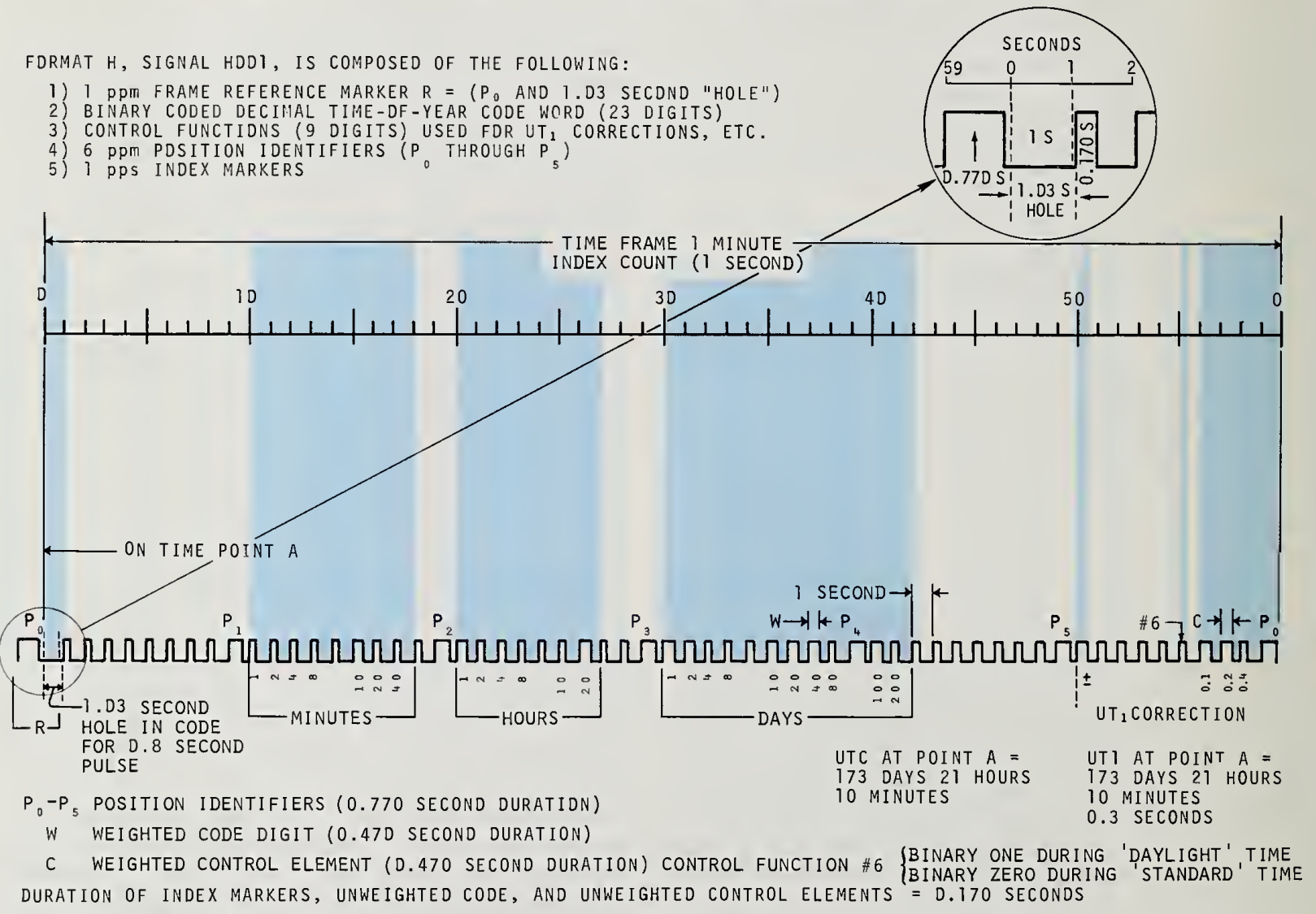

NOTE: BEGINNING OF PULSE IS REPRESENTED BY POSITIVE-GOING EDGE.

Figure 2A. WWV and WWVH time code format. 
the time code format. The six position identifiers are denoted by symbols $\mathbf{P}_{1}, \mathbf{P}_{2}, P_{3}, P_{4}, P_{5}$, and $P_{0}$. The minutes, hours, days, and UT1 sets are marked by brackets, and the applicable weighting factors are printed beneath the coded pulses in each BCD group. With the exception of the position identifiers, all uncoded pulses are set permanently to binary 0 .

The first ten seconds of every frame always include the 1.03 -second hole followed by eight uncoded pulses and the position identifier $\mathrm{P}_{1}$. The minutes set follows $\mathrm{P}_{1}$ and consists of two BCD groups separated by an uncoded pulse. Similarly, the hours set follows $P_{2}$. The days set follows $\mathrm{P}_{3}$ and extends for two pulses beyond $\mathrm{P}_{4}$ to allow enough elements to represent three decimal digits. The UT1 set follows $P_{5}$, and the last pulse in the frame is always Po.

In figure $2 \mathrm{~A}$, the least significant digit of the minutes set is $(0 \times 1)+(0 \times 2)+(0 \times 4)+(0 \times 8)=0$; the most significant digit of that set is $(1 \times 10)+(0 \times 20)+(0 \times$ $40)=10$. Hence, at the beginning of the 1.03 -second hole in that frame, the time was exactly 10 minutes past the hour. By decoding the hours set and the days set, it is seen that the time of day is in the 21 st hour on the 173rd day of the year. The UT 1 correction is +0.3 second. Therefore, at point $\mathrm{A}$, the correct time on the UT1 scale is 173 days, 21 hours, 10 minutes, 0.3 second.

\section{A. WWVB Time Code}

The WWVB time code is generated by shifting the power of the $60-\mathrm{kHz}$ carrier. The carrier power is reduced $10 \mathrm{db}$ at the beginning of each second and restored to full power 200 milliseconds later for a binary zero, 500 milliseconds later for a binary one, and 800 milliseconds later for a reference marker or position identifier. Certain groups of pulses are encoded to represent decimal numbers which identify the minute, hour, and day of year. The binary-to-decimal weighting scheme is 8-4-2-1 with the most significant binary digit transmitted first. Note that this weighting sequence is the reverse of the WWV/WWVH code. The BCD groups and their basic decimal equivalents are tabulated below:
BINARY GROUP

Weight:

\begin{tabular}{ccccc}
8 & 4 & 2 & 1 & EQUIVALENT \\
\hline 0 & 0 & 0 & 0 & 0 \\
0 & 0 & 0 & 1 & 1 \\
0 & 0 & 1 & 0 & 2 \\
0 & 0 & 1 & 1 & 3 \\
0 & 1 & 0 & 0 & 4 \\
0 & 1 & 0 & 1 & 5 \\
0 & 1 & 1 & 0 & 6 \\
0 & 1 & 1 & 1 & 7 \\
1 & 0 & 0 & 0 & 8 \\
1 & 0 & 0 & 1 & 9
\end{tabular}

The decimal equivalent of each group is derived by multiplying the individual binary digits by the weight factor of their respective columns and then adding the four products together. For example, the binary sequence 1001 in 8-4-2-1 code is equivalent to $(1 \times 8)+(0 \times 4)+(0 \times$ $2)+(1 \times 1)=8+0+0+1=9$, as shown in the table. If fewer than nine decimal digits are required, one or more of the high-order binary digits may be dispensed with.

Once every minute, in serial fashion, the code format presents BCD numbers corresponding to the current minute, hour, and day on the UTC scale. Two BCD groups identify the minute ( 00 through 59 ); two groups identify the hour (00 through 23 ); and three groups identify the day of year (001 through 366 ). When representing units, tens, or hundreds, the basic 8-4-2-1 weights are multiplied by 1,10 , or 100 respectively. The coded information refers to the time at the beginning of the one-minute frame. Within each frame, the seconds may be determined by counting pulses.

Every new minute commences with a frame reference pulse which lasts for 0.8 second. Also, every ten-second interval within the minute is marked by a position identifier pulse of 0.8 -second duration.

UT 1 corrections to the nearest 0.1 second are transmitted at seconds 36 through 44 of each frame. Coded pulses at 36,37 , and 38 seconds indicate the positive or negative relationship of UT1 with respect to UTC. Pulses at 36 and 38 seconds are transmitted as binary ones only if UT1 is early with respect to UTC, in which case a correction must be added to the UTC signals to obtain UT1. The pulse transmitted at 37 seconds is a binary one if UT1 is late with respect to UTC, in which case the required UT1 correction must then be subtracted. The magnitude of the UT 1 correction is transmitted as a BCD group at 40, 41, 42 , and 43 seconds. Because UT1 corrections are expressed in tenths of seconds, the basic 8-4-2-1 weight of that particular binary group is multiplied by 0.1 to obtain its proper decimal equivalent.

Figure $3 \mathrm{~A}$ shows a sample frame of the time code in rectified or dc form. The negative-going edge of each pulse coincides with the beginning of a second. Position identifiers are labeled $\mathbf{P}_{1}, \mathbf{P}_{\mathbf{2}}, \mathbf{P}_{\mathbf{3}}, \mathbf{P}_{\mathbf{4}}, \mathbf{P}_{5}$, and $\mathbf{P}_{\mathbf{0}}$. Brackets show the demarcation of the minutes, hours, days, and UT1 sets. The applicable weight factor is printed beneath the coded pulses in each BCD group. Except for the position identifiers and the frame reference marker, all uncoded pulses are binary zeros.

In figure $3 \mathrm{~A}$, the most significant digit of the minutes set is $(1 \times 40)+(0 \times 20)+(0 \times 10)=40$; the least significant digit of that set is $(0 \times 8)+(0 \times 4)+(1 \times 2)$ $+(0 \times 1)=2$. Thus, at the beginning of the frame, UTC was precisely 42 minutes past the hour. The sets for hours and days reveal further that it is the 18th hour of the 258th day of the year. The UT 1 correction is -0.7 second, so at the beginning of the frame the correct time on the UT1 scale was 258 days, 18 hours, 41 minutes, 59.3 seconds. 


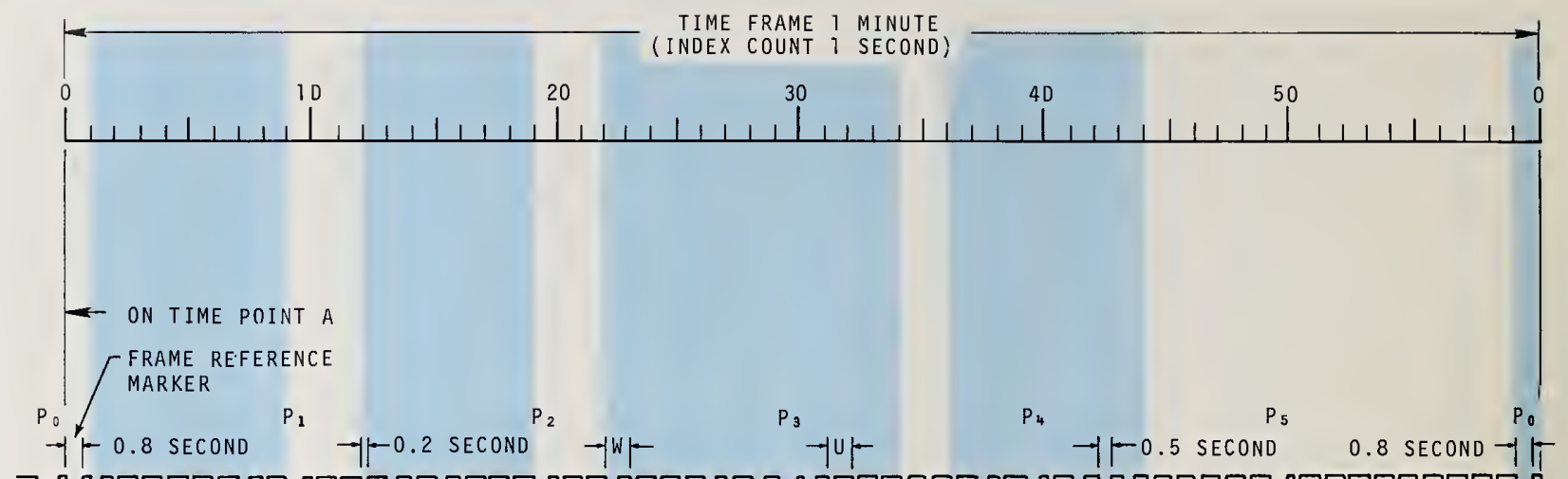

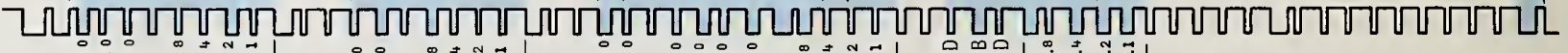

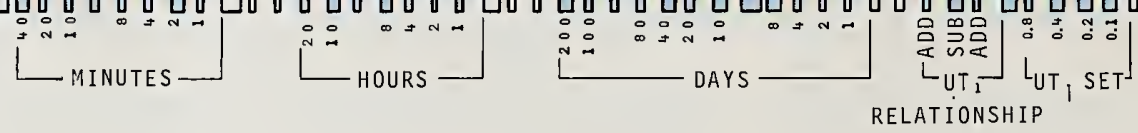

BINARY CODED DECIMAL TIME-OF-YEAR CODE WORD (23 DIGITS)

CONTROL FUNCTIONS ( 15 DIGITS) USED FOR UT 1 CORRECTIONS

6 PPM POSITION IDENT IFIER MARKERS AND PULSES ( $\mathrm{P}_{0}$ THRU $\mathrm{P}_{5}$ )

UTC AT POINT A

258 DAYS

18 HOURS

42 MINUTES

(REDUCED CARRIER 0.8 SECOND DURATION PLUS 0.2 SECOND DURATION PULSE)

W - WEIGHTED CODE DIGIT (CARRIER RESTORED IN 0.5 SECOND - BINARY ONE)

U - UNWEIGHTED CODE DIGIT (CARRIER RESTORED IN 0.2 SECOND - 8INARY ZERO)

NOTE: BEGINNING OF PULSE IS REPRESENTED BY NEGATIVE - GOING EDGE.
UT 1 AT POINT A

258 DAYS

18 HOURS

41 MINUTES

59.3 SECONDS

$9 / 75$

Figure 3A. WWVB time code format. 


\title{
Telephone Time of Day Service
}

WWV and WWVH broadcasts may be heard via telephone. Since the RF carriers cannot be detected over telephone circuits, only the audio portion of the broadcasts may be heard. Accuracy of the time signals as received anywhere in the contiguous 48 states is 30 milliseconds or better.

By calling (303) 499-7111 in Boulder, Colorado, the user will hear the live broadcasts as transmitted from WWV. This service is automatically limited to three minutes per call. Similar time-of-day broadcasts from WWVH can be heard by dialing (808) 335-4363 on the island of Kauai, Hawaii. NOTE: These are long distance toll calls for those users outside the local dialing area.

\section{About the Announcer's}

The station identification and time-of-day announcements are pre-recorded — not "live." The regular announcer for WWV is Mr. Don Elliott of Atlanta, Georgia. Mrs. Jane Barbe, also of Atlanta, is the announcer for WWVH.

\section{Tours}

Guided tours are available at all of the NBS radio stations. Visiting hours at WWV, WWVB, and WWVL are every Wednesday, except holidays, from 2:00 to 4:00 p.m. Special tours may be scheduled at other times only by prior arrangement with the engineer-in-charge. WWVH does not have regularly scheduled visiting hours - arrangements for visiting the site should be made in advance.

Tours of the NBS Boulder Laboratories, including visits to the atomic clock and the other dissemination services, are available. Information can be obtained from the Program Information Office, NBS, Boulder, CO 80302.

\section{Inquiries About the Stations}

Correspondence pertaining directly to station operations may be addressed to:

\author{
Engineer-in-Charge \\ 2000 East County Road 58 \\ Fort Collins, CO 80521 \\ Telephone: (303) 484-2372 \\ Engineer-in-Charge \\ NBS Radio Radio Station WWVH \\ P. O. Box 417 \\ Kekaha, Kauai, HI 96752 \\ Telephone: (808) 335-4361
}

NBS Radio Stations WWV/WWVB/WWVL 
U.S. DEPARTMENT OF COMMERCE

National Bureau of Standards

Washington. D.C. 20234

OFFICIAL BUSINESS

PENALTY FOR PRIVATE USE, $\$ 300$
POSTAGE AND FEES PAID

USS. DEPARTMENT OF COMMERCE

CDM-215

SPECIAL FOURTH-CLASS RATE BOOK

U.S.MAIL 